Revista Destaques Acadêmicos, Lajeado, v. 12, n. 3, 2020. ISSN 2176-3070

DOI: http://dx.doi.org/10.22410/issn.2176-3070.v12i3a2020.2690

http://www.univates.br/revistas

\title{
IMPLEMENTAÇÃO DA SISTEMATIZAÇÃO DA ASSISTÊNCIA DE ENFERMAGEM EM UM SERVIÇO DE URGÊNCIA E EMERGÊNCIA: UM RELATO DE EXPERIÊNCIA
}

\author{
Géssica Genesini ${ }^{1}$, Luís Felipe Pissaia ${ }^{2}$, Juliana Thomas ${ }^{3}$, \\ Caroline Alessandra Cerutti ${ }^{4}$
}

Resumo: Este estudo possui o objetivo de compartilhar um relato de experiência sobre a implementação da Sistematização da Assistência de Enfermagem em um serviço de urgência e emergência privado do interior do Rio Grande do Sul, Brasil. Trata-se de um relato de experiência, qualitativo, descritivo e exploratório. O local de coleta de dados foi um serviço de urgência e emergência privado do interior do estado do Rio Grande do Sul Brasil. O estudo foi realizado entre os meses de março e junho de 2020 e para a análise dos resultados seguiu aproximações com a Análise de Conteúdo. Os resultados são estruturados em três diferentes momentos ou fases de estudo. No primeiro foi realizada a análise criteriosa do modelo de Sistematização da Assistência de Enfermagem realizada no serviço, no segundo indagou-se sobre a preparação da equipe quanto à implementação da metodologia de trabalho, de forma que um momento de capacitação ocorresse. No terceiro momento, apresenta-se a nova proposta de documento para a realização do método de trabalho, de modo que contempla a necessidade do serviço e da área específica da enfermagem, bem como sua posterior avaliação. Dessa forma, acredita-se que a realização desse relato de experiência pode inspirar outras equipes e serviços de saúde em realizar a implantação ou implementação da Sistematização da Assistência de Enfermagem por meio do modelo apresentado.

Palavras-chave: Sistematização da Assistência de Enfermagem. Urgência e Emergência. Processo de Enfermagem. Organização de Serviço de Saúde.

1 Acadêmica de Enfermagem. ORCID: https://orcid.org/0000-0002-7254-7473. Universidade do Vale do Taquari - UNIVATES, Brasil. E-mail: gessicagenesini@gmail.com

2 Enfermeiro. Doutorando em Ensino. ORCID: https://orcid.org/0000-0002-4903-0775. Universidade do Vale do Taquari - UNIVATES, Brasil. E-mail: lpissaia@universo.univates.br

3 Enfermeira. Mestre em Ensino na Saúde. ORCID: https://orcid.org/0000-0003-0340-9883. Universidade Federal de Ciências da Saúde de Porto Alegre - UFCSPA, Brasil. E-mail: juliana. thomas@univates.br

4 Enfermeira. ORCID: https://orcid.org/0000-0003-1251-2807. Universidade do Vale do Taquari - UNIVATES, Brasil. E-mail: carolinecerutti@hotmail.com 


\section{Introdução}

Os serviços de urgência e emergência apresentam-se como um ambiente, na maioria das vezes, de tensão e stress, onde o profissional da saúde precisa estar atento e ser preciso na sua conduta para eficácia do atendimento, priorizando a saúde e integridade do indivíduo que está vulnerável naquele momento, conforme afirmam Pissaia e Costa (2020). Segundo Barbosa e Castro (2020) as ações de acolhimento por parte da enfermagem, fazem com que o paciente sinta confiança e consiga vincular-se com quem está o atendendo, priorizando não somente os procedimentos técnicos como também de cuidado e necessidades de demanda do paciente.

Dessa forma, o acolhimento em serviços de urgência e emergência configura uma maior segurança para o paciente em atendimento e conforme Pissaia e Costa (2019) asseguram um ambiente seguro para a realização do primeiro atendimento e de todos os encaminhamentos necessários ao caso, incluindo a remoção do local do acidente ou incidente, até a instituição de apoio. Assim, Pissaia et al. (2020) discutem sobre a importância da formação integral do profissional de enfermagem, capaz de atuar frente às diferentes demandas e ser resolutivo sobre o caso acompanhado.

Os serviços de urgência e emergência atuam frente à situação de risco pessoal e profissional, realizando atendimentos diretamente em situações de acidentes ou incidentes nos diversos cenários, que conforme Pissaia e Costa (2019) exigem uma organização extra por parte da equipe de enfermagem. A organização da equipe mencionada pelos autores supracitados se refere aos processos e condutas de atendimento que são acionados após a ocorrência de um chamado para atendimento de urgência ou emergência, fato que se torna importante ao qualificar a assistência realizada.

Nesse contexto de organização da assistência de enfermagem, Mesquita e Tavares (2020) versam sobre a existência das teorias de enfermagem, cujo arcabouço científico embasam a conduta da área por meio de estratégias testadas e validadas anteriormente. Dentre as teorias disponíveis, Pissaia et al. (2020) destacam a "Teoria das Necessidades Humanas Básicas" de autoria da enfermeira Wanda Horta que preconizou a organização da assistência de enfermagem brasileira por meio do Processo de Enfermagem (PE).

Para Tannure e Pinheiro (2014) o PE é composto por cinco etapas, inter-relacionadas que são: Histórico de Enfermagem, etapa responsável por conduzir os registros dos sinais e sintomas observados no paciente durante o acolhimento e exame físico; A segunda etapa é a de Diagnósticos de Enfermagem, cujo objetivo é elencar os principais problemas a serem solucionados no caso, sempre com o auxílio de literatura científica; A Prescrição de Enfermagem, é a terceira etapa e responsável por elencar as procedimentos necessários para solucionar os Diagnósticos de Enfermagem; A quarta etapa é a de Implementação do plano de cuidados, ou seja, o enfermeiro descreverá 
os procedimentos realizados junto ao paciente; E, por fim, a Avaliação de Enfermagem, quinta e última etapa que conduz à uma avaliação final do PE realizado, indicando a eficácia ou não do acompanhamento.

Dessa forma, para Santana (2020) a realização do PE no Brasil trata-se de um avanço para a área da enfermagem, de modo que o cuidado foi qualificado com a inserção das etapas nos modelos de organização assistencial das instituições de saúde. Contudo, em 2009 o Conselho Federal de Enfermagem (COFEN) instituiu a Resolução $\mathrm{n}^{\circ} 358$ que preconiza a implantação da Sistematização da Assistência de Enfermagem (SAE) em ambientes públicos e privados em que ocorra a atuação de profissional da enfermagem, conforme indicam Tannure e Pinheiro (2014).

Para Fontana e Pissaia (2018) a implantação da SAE trouxe consigo a obrigatoriedade de realização do $\mathrm{PE}$, ou seja, o próprio COFEN indica que a Sistematização ocorra por meio da aplicação das cinco etapas como meio de integralizar o cuidado. Assim, Costa e Silva (2020) argumentam que a enfermagem brasileira sofreu profundas mudanças no padrão assistencial por ocorrência da implantação da SAE, intuindo que desta forma a qualificação torna-se possível nos serviços da saúde.

Dessa forma, Pissaia e Costa (2019) articulam a importância da SAE para os ambientes de urgência e emergência, configurando não somente um modelo organizacional do trabalho da enfermagem, mas uma forma de garantir que a segurança do paciente seja resguardada. A construção de um modelo de atuação profissional baseado nos preceitos das SAE impera na qualidade da assistência oferecida para a população, de modo que os vínculos sejam fortalecidos, bem como a resolutividade dos casos, segundo indicam Santos e Valente (2020).

Sendo assim, o objetivo desse estudo é compartilhar um relato de experiência sobre a implementação da Sistematização da Assistência de Enfermagem em um serviço de urgência e emergência privado do interior do Rio Grande do Sul, Brasil.

\section{Metodologia}

Trata-se de um relato de experiência, qualitativo, descritivo e exploratório. O local de coleta de dados foi um serviço de urgência e emergência privado do interior do estado do Rio Grande do Sul Brasil.

O local de estudo é um serviço de urgência e emergência privado que presta assistência a todos os gêneros e em todas as fases da vida. $\mathrm{O}$ serviço possui 18.859 clientes no balanço mensal do mês de abril de 2020. O estudo foi realizado entre os meses de março e junho de 2020. Como instrumentos de coleta de dados, foi utilizada a "Ficha de regulação médica" existente no serviço, sendo a coleta realizada entre os meses de abril e maio do ano de 2020.

Os recursos humanos que compõem o serviço é 01 enfermeira coordenadora que permanece 40 horas semanais acompanhando a equipe e 04 
equipes, sendo que essas realizam turnos de 12 horas. A equipe é composta por dois modelos: Equipe básica: 01 enfermeiro, 01 técnico de enfermagem, 01 condutor-socorrista; Equipe avançada: 01 técnico de enfermagem, 01 médico, 01 condutor-socorrista. Pertence ainda a equipe, 03 atendentes telefônicas que fazem turnos de 6 horas. Todos os profissionais registram as suas práticas e compartilham a necessidade de estruturar o modelo abordado no estudo.

Os dados serão analisados com aproximações da Análise de Conteúdo de Bardin (2016), sendo que as informações foram coletadas, transcritas e reunidas por pontos focais compatíveis. Os pontos focais originaram as categorias temáticas que buscaram apresentar os resultados e suas respectivas discussões em seção específica desse estudo.

Este relato de experiência seguiu os preceitos éticos para pesquisa com seres humanos preconizados pela Resolução 466 de 2012 do Conselho Nacional de Saúde sendo respeitadas as informações coletadas, bem como a identidade dos sujeitos e do serviço pesquisado. Buscando preservar a identidade do serviço pesquisado, serão suprimidas as marcas ou identidade nos documentos aqui apresentados e discutidos.

\section{Resultados e Discussão}

Nesta seção serão apresentados os resultados e discussões inerentes a esse relato de experiência. As informações são apresentadas por meio de categorias temáticas, sendo a primeira intitulada de "Avaliação do modelo de Sistematização da Assistência de Enfermagem vigente" sendo preconizado uma descrição de como a SAE é realizada atualmente no serviço de urgência e emergência. A segunda categoria foi nomeada de "Capacitação aos profissionais de enfermagem" onde se descreve a pré-implantação da SAE, demonstrando ao leitor a preparação da equipe ao novo processo. E, por fim, a terceira categoria intitulada de "Implementação do novo modelo da Sistematização da Assistência de Enfermagem", espaço destinado aos autores articularem a implementação do novo processo no ambiente estudado.

\subsection{Avaliação do modelo de Sistematização da Assistência de Enfermagem vigente}

Nesta categoria serão apresentados os resultados e as discussões inerentes ao modelo de SAE vigente no serviço de urgência e emergência estudado, de forma que o leitor identifique como se encontra o cenário de atuação da equipe de enfermagem. A realização da análise do modelo vigente torna-se necessária para evidenciar a ocorrência de situações passíveis de melhoria no que diz respeito à articulação da SAE no ambiente de trabalho da equipe de enfermagem.

A avaliação dos modelos de atuação em enfermagem é eficaz sob o prisma da qualificação da assistência oferecida ao paciente que conforme Silva 
et al. (2020) oferecem uma visão geral do espaço destinado para o profissional de enfermagem exercer sua organização. Ainda, para Pissaia, Costa e Thomas (2020) ao vivenciar os processos realizados pelo serviço de saúde, é possível introduzir e articular novos modelos organizacionais, principalmente quando se trata da SAE.

Dessa forma, os registros do serviço de urgência e emergência são realizados de modo manual, após cada atendimento em uma folha padrão do serviço que se encontra impressa e disponível na área de trabalho dos profissionais. A folha padrão do atendimento é chamada de "Ficha de regulação médica", sendo impressa com os dados do cliente e disponibilizados no cabeçalho da folha.

Os dados de identificação do paciente são coletados no cadastro interno do serviço de saúde, incluindo modalidade do plano contratado e o motivo principal do chamado de urgência ou emergência ou translado. Esse processo é gerenciado pelos atendentes da central telefônica que são profissionais com formação em técnico em enfermagem e que possuem capacitação para conduzir o pré-atendimento, passando as informações para a equipe de enfermagem e médica de plantão, bem como o endereço e indicação de ponto de referência, para agilizar a chegada do atendimento móvel, caso necessário.

A Ficha de regulação médica é composta por espaços direcionados para anotar qual tipo de socorro foi solicitada (urgência trauma/clínica, emergência trauma/clínica, regulação médica/prévia, e ainda se a equipe está em outro atendimento), qual ambulância foi utilizada e se o chamado possui ou não cobertura pelo serviço, e elencado ainda se houve algum custo para o paciente. Outro campo indicado para o preenchimento, é o dos sinais vitais (horário, pressão arterial $(\mathrm{mmHg})$, frequência cardíaca $(\mathrm{bpm})$, frequência respiratória $(\mathrm{mpm})$, saturação de $\mathrm{O}^{2}(\%)$, temperatura $\left({ }^{\circ} \mathrm{C}\right)$, glicemia HGT $\left.(\mathrm{mg} / \mathrm{dl})\right)$. Ao lado da tabela de Sinais Vitais é apresentada a Escala de Coma de Glasgow (abertura ocular, resposta verbal, resposta motora, pupilas) e verificam-se também algumas linhas para descrição do atendimento, realizado pelo médico atuante. As informações descritas podem ser verificadas abaixo, na Imagem 1, em que se apresenta parte do documento digitalizado: 
Imagem 1. Registro inicial da equipe de enfermagem e médica.

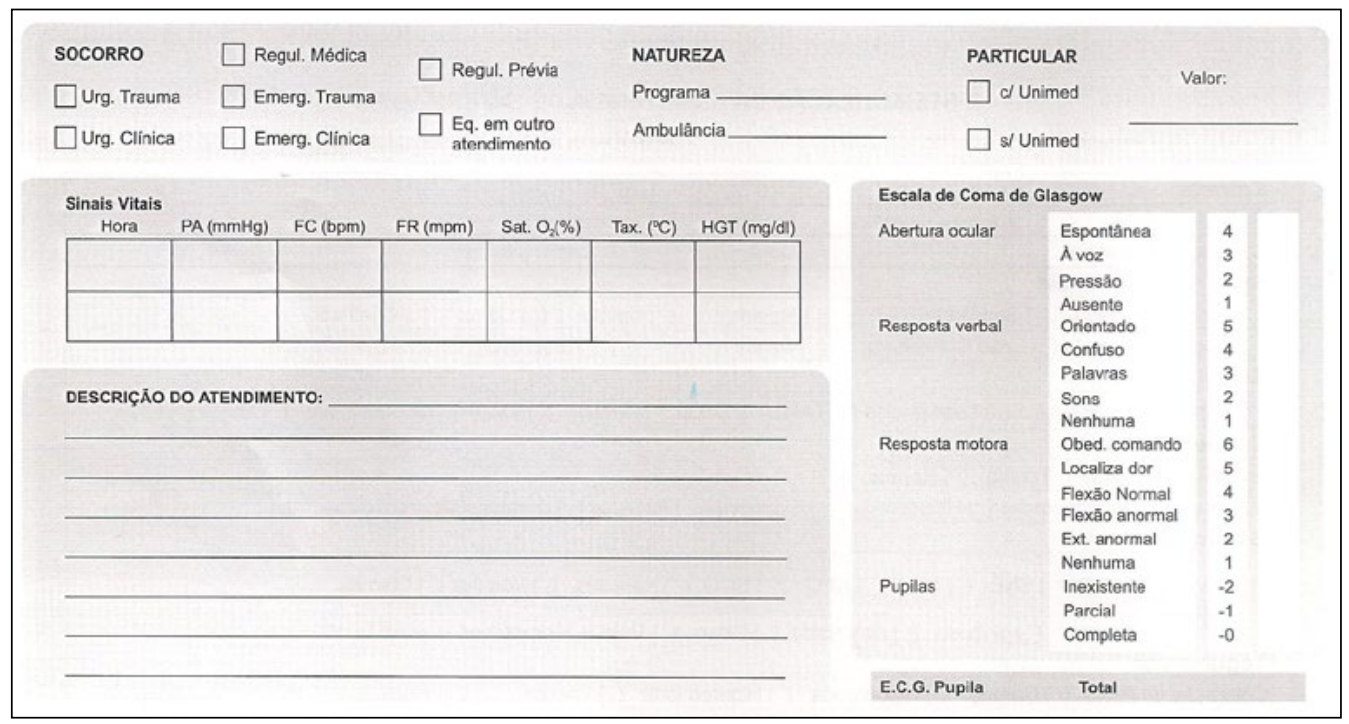

Fonte: Pesquisadores (2020).

Para Pissaia e Costa (2020) os dados básicos do paciente são imprescindíveis para o sucesso no atendimento em urgência e emergência, pelo fato que qualificam o processo ao contemplar o item de segurança do paciente. De fato, ao inserir múltiplas informações sobre o paciente, o atendimento tornase mais seguro e resolutivo conforme indica Santana (2020) que pactua sobre a necessidade de um acolhimento de qualidade e fidedigno com a realidade do caso.

A seguir, na Imagem 2, é possível observar o espaço destinado para a conduta médica, que deve ser preenchida, assinada e carimbada pelo médico atendente de plantão. Em campo abaixo, outro espaço é reservado para a evolução de enfermagem, também preenchido, assinado e carimbado pelos profissionais (enfermeiro ou técnico em enfermagem) que atuaram no atendimento. A última informação do lado da frente do documento é reservada ao termo de responsabilidade, onde se solicita a assinatura do paciente ou responsável, declarando receber do serviço o atendimento. 
Imagem 2. Registros do atendimento.

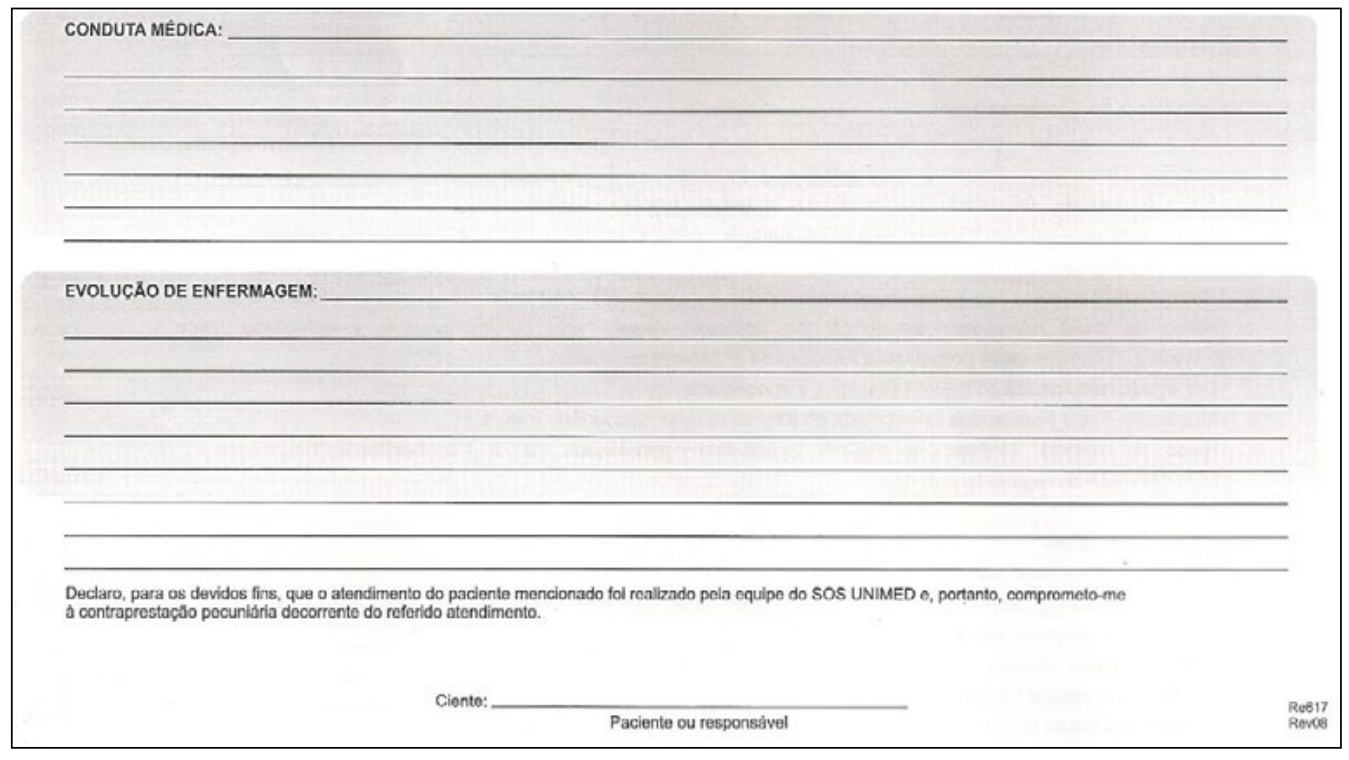

Fonte: Pesquisadores (2020).

Conforme indicado pelos autores Tannure e Pinheiro (2014), o campo de registro profissional é reservado para as informações pertinentes a assistência realizada no momento do atendimento, sendo descrito detalhadamente cada procedimento. Dessa forma, o registro profissional torna-se o comprovante de realização do procedimento ou conduta realizada ao paciente no decorrer do plano de cuidados aplicado, conforme salientam Fontana e Pissaia (2018).

No verso da ficha de regulação médica pode ser verificado em primeiro plano o Controle de Gastos no Atendimento, onde são descritos todo e qualquer material ou medicamento utilizado no ato do atendimento, sendo destacada em tabela a quantidade de cada item. Ainda há uma opção para marcar caso não seja utilizado material ou medicamento, para que depois possa ser lançado na ficha do paciente, bem como repor tais materiais na ambulância, de preferência no mesmo turno de uso, deixando organizado e completo para os próximos atendimentos. Partindo dessa informação, percebe-se a importância de articular a gestão eficaz dos materiais e medicamentos no espaço de trabalho do enfermeiro, de modo que a assistência siga os preceitos da resolutividade, conforme indicam Santos e Valente (2020).

Posteriormente, na Imagem 3 destacada abaixo, é apresentado o restante do verso da ficha de regulação, sendo nominada como "Sistematização da Assistência de Enfermagem", espaço reservado para a realização da SAE após cada atendimento. 
Imagem 3. Sistematização da Assistência de Enfermagem.

\section{SISTEMATIZAÇÄO DA ASSISTÊNCIA DE ENFERMAGEM}

Preenchimento quando realizado atendimento do enfermeiro, conforme resoluçăo COFEN 272/2002

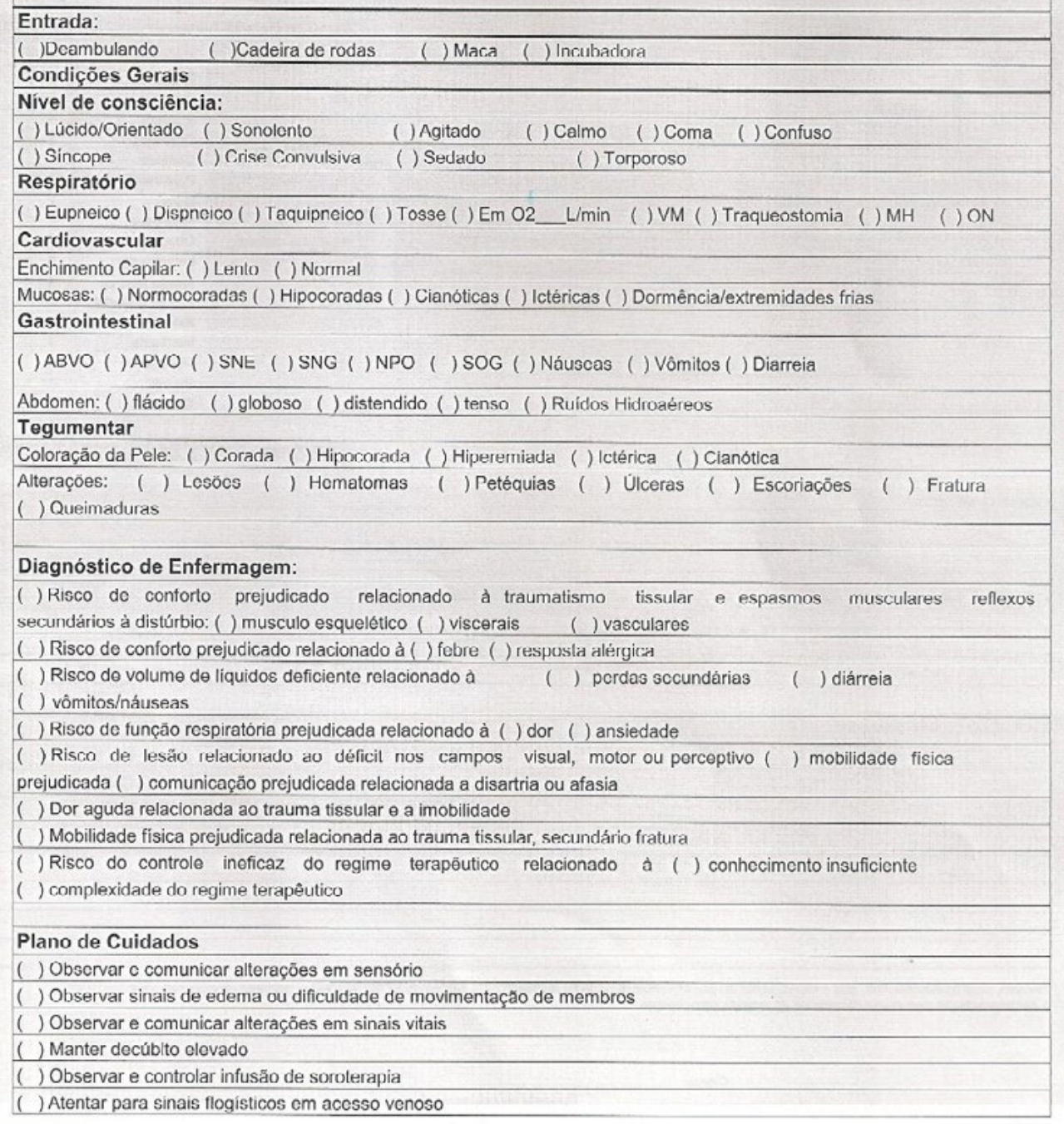

Fonte: Pesquisadores (2020).

O campo de realização da SAE verificado na Imagem 3 é reservado para preenchimento pelo enfermeiro responsável pelo atendimento do caso de urgência ou emergência. As opções disponíveis oferecem uma avaliação a partir do exame físico e sinais e sintomas que o paciente apresenta no momento do atendimento, bem como a marcação dos Diagnósticos de Enfermagem e o Plano de Cuidados. Dessa forma, se verifica que a SAE não é realizada em sua completude, fato que para Barbosa e Castro (2020) não é considerado o ideal 
em um serviço de saúde, por interferir na qualidade da assistência e vinculação com o paciente.

\subsection{Capacitação aos profissionais de enfermagem}

Está categoria é responsável por descrever a pré-implementação da SAE no serviço de urgência e emergência, intuindo sobre a necessidade de capacitar os profissionais da equipe de enfermagem sobre o novo processo. Dessa forma, compreende-se que promover uma capacitação aos profissionais de enfermagem, com o intuito de direcionar a retomar os itens básicos que precisam conter em uma evolução, bem como recomendações sobre como devem proceder com os registros, é de suma importância para a posterior implementação da SAE.

Ao implementar a SAE, o serviço de saúde precisa capacitar os profissionais de enfermagem sobre a realização da metodologia de trabalho e segundo Costa e Silva (2020) a explicação deve ser simples e objetiva, possibilitando a realização prática do processo. Assim, Tannure e Pinheiro (2014) consideram importante a introdução de capacitações no contexto de implantação e implementação da SAE, de modo que alguns profissionais nunca presenciaram a realização da metodologia no mercado de trabalho.

Dessa forma, os pesquisadores realizarão a capacitação em formato de palestra explicativa, utilizando o apoio da ferramenta do PowerPoint para contextualizar as principais oportunidades de melhoria nos registros realizados atualmente pela equipe e sugestões de como proceder da forma mais adequada. $\mathrm{O}$ momento terá uma carga horária de 3 horas, contemplando as quatro equipes atuantes (dia e noite $\mathrm{A}$, dia e noite $\mathrm{B}$ ), direcionada para enfermeiros e técnicos em enfermagem. A realização de experimentações no contexto de ensino de determinado processo é capaz de auxiliar no processo de ensino e aprendizagem dos participantes, construindo o conhecimento de forma conjunta e por meio de exemplos conforme descrevem Pissaia, Costa e Thomas (2020).

Com a capacitação, espera-se retomar a condução das evoluções de enfermagem realizadas nos atendimentos do serviço de urgência e emergência, com a finalidade de garantir a partilha de informações, qualidade das evoluções, destacarem que é um documento permanente na instituição com evidência legal, ainda passível de auditoria. Nesse sentido, Santos e Valente (2020) comentam sobre a necessidade dos profissionais da enfermagem compreender a importância e validade legal que os registros de atendimentos possuem para a sociedade.

No conteúdo será destacado o amparo legal pela Resolução do COFEN $\mathrm{n}^{\mathrm{o}} 429 / 12$, art. 68 tens como direito registrar no prontuário, e em outros documentos próprios da enfermagem, informações referentes ao processo de cuidar da pessoa. Ainda ser de sua responsabilidade e dever, art.25, registrar no 
Prontuário do Paciente as informações inerentes e indispensáveis ao processo de cuidar, no art. 41, prestar informações, escritas e verbais, completas e fidedignas necessárias para assegurar a continuidade da assistência. Outro fator em destaque, como tratado no art. 35, que fica proibido registrar informações parciais e inverídicas sobre a assistência prestada.

Deste modo, partimos do pressuposto da importância da organização da escrita. Em todo registro é preciso respeitar os limites das linhas, não podendo haver parágrafo ou espaços em branco, não é permitido rasuras e é fundamental usar a mesma caneta. Importante também que a evolução de enfermagem deve ser preenchida pelo profissional que executou o atendimento, em seguida assinar e carimbar, evitando anotações posteriores. As exigências quanto à disposição das informações são necessárias para a segurança e defesa ética do plano de cuidados prestado ao paciente, conforme asseguram Tannure e Pinheiro (2014).

Outro ponto a ser destacado na capacitação é o conteúdo da evolução de enfermagem, como: dados do paciente, onde ele se encontra (domicílio, hospital, transferência de instituição), em caso de remoções (internação ou alta-hospitalar) relatar se teve presença de acompanhante responsável ou não, se foi necessário monitorização dos sinais vitais, quais foram os resultados das aferições. Observar e anotar sintomas e condições de locomoção (deambulando, com auxílio, cadeira de rodas, maca) e outras condições gerais que ele apresenta (nível de consciência, humor, atitudes, coloração da pele). Descrever o uso de dispositivos e localização (sonda, curativos, acessos), bem como as queixas trazidas pelo paciente ou responsável e os cuidados prestados durante o atendimento. Em casos de intercorrências quais foram os procedimentos adotados (piora clínica). Respostas dos pacientes quanto às ações realizadas, qual foi o destino final, o profissional responsável e setor do recebimento, também devem ser descritos na evolução. Para Fontana e Pissaia (2018) ao coletar as informações do paciente, o mesmo vincula-se a equipe e abre várias oportunidades de realização das intervenções pertinentes ao plano de cuidados.

Na capacitação serão apresentados e discutidos alguns casos fictícios para exemplificar como é feita a realização da SAE, pontos negativos, positivos e sugestões de melhoria. Os três casos fictícios serão apresentados abaixo e após cada um será sugerido modelos de escrita indicadas para a realização de uma evolução completa:

Paciente L.A., 88 anos, sexo masculino, lúcido, agitado, corado. Saturando $94 \%$ em cateter nasal a $21 /$ min. Eliminação vesical e intestinal em fralda. Paciente removido do Hospital Muçum para Roca Sales. Sem intercorrências (evolução de remoção).

Indicação de evolução: Avaliação céfalo-caudal: observar e anotar as condições gerais do paciente (condição neurológica, aspecto e coloração da 
pele); evoluir os dispositivos que estão em uso (cateter nasal, sonda nasoenteral, cateter periférico); condições de locomoção (deambulando, com auxílio, cadeira de rodas, maca); elencar os cuidados realizados; descrever as intercorrências; informar se durante a remoção teve acompanhante responsável.

Paciente L.M., 45 anos, sexo masculino, refere sensação de malestar e dor abdominal intensa. Atendimento realizado no domić́lio. Medicado com 0,5ml de morfina SC (evolução de atendimento).

Indicação de evolução: Avaliação céfalo-caudal: identificar as queixas do paciente (tudo o que ele refere, dados informados pelos familiares); observar e anotar as condições gerais do paciente (condição neurológica, aspecto e coloração da pele); evoluir se o paciente possui dispositivos em uso (cateter nasal, sonda nasoenteral, cateter periférico); condições de locomoção (deambulando, com auxílio, cadeira de rodas, maca); local do atendimento (residência ou clínica); descrever a realização da aplicação do medicamento (diluição, local da aplicação, se ficou em observação, se teve algum tipo de reação); descrever as intercorrências; informar se havia acompanhante responsável ou estava sozinho.

Cliente C.K., sexo feminino, 89 anos, hipocorada, agitada, em repouso no leito do Hospital Nossa Senhora. Paciente febril $(38,5)$. Com acesso periférico em MSD infundindo adrenalina $10 \mathrm{ml} / \mathrm{h}$ em bomba de infusão. Diagnóstico de acidente vascular hemorrágico. Removida com a UTI móvel para o Hospital São José. Sem intercorrências.

Indicação de evolução: Avaliação e registro dos sinais vitais em três momentos (início da remoção, durante e no momento da entrega ao local do destino); observar e anotar as condições gerais do paciente (condição neurológica, aspecto e coloração da pele); comunicação não verbal (expressão de algia, desconforto); observar e anotar as condições gerais do paciente (condição neurológica, aspecto e coloração da pele); evoluir se o paciente possui dispositivos em uso (cateter nasal, sonda nasoenteral, cateter periférico); condições de locomoção (deambulando, com auxílio, cadeira de rodas, maca); elencar os cuidados realizados; descrever as intercorrências; informar se havia acompanhante responsável ou não e no destino final, identificar o profissional responsável e setor do recebimento.

A estruturação de casos fictícios torna-se uma estratégia eficaz para a realização de experimentações sobre determinado conteúdo conforme indicam Pissaia e Costa (2020), pactuando ainda que ao realizar as práticas, os profissionais ampliam o olhar sobre o paciente. No que tange a SAE, Santos e Valente (2020) concordam que a realização do modelo organizacional 
em capacitações é a melhor maneira de qualificar a prática, bem como a sensibilização da equipe de enfermagem sobre a implantação do processo.

\subsection{Implementação do novo modelo da Sistematização da Assistência de Enfermagem}

A presente categoria é responsável por descrever o processo de implementação da SAE no serviço de urgência e emergência. Dessa forma, durante a capacitação será apresentado o novo modelo da ficha de regulação médica, e como se conduzirá a partir da reformulação do documento, incluindo especialmente todas as etapas da SAE. Para Mesquita e Tavares (2020) a identificação de oportunidades de melhoria que originam o processo de implementação da SAE é fortuito sob o ponto de vista da qualificação constante do serviço de saúde.

Os profissionais serão acompanhados e terão todas suas dúvidas e questionamentos sanados sobre o preenchimento, buscando a melhoria integral, bem como uma regularidade nos registros, contemplando todas as etapas e ainda informações pertinentes sobre o atendimento e o paciente. Segundo Santana (2020) é necessário um acompanhamento da equipe de enfermagem após a implementação da SAE como modelo integral de organização do trabalho, pois as dúvidas surgem no decorrer de sua realização.

Como exemplificado a seguir, na Imagem 4, o início da ficha continua com os itens no cabeçalho sobre os dados pessoais, de cobertura do plano de cada paciente e informações do referido atendimento. O campo "socorro" permanece com os mesmos subitens, indicando o tipo de atendimento solicitado (urgência trauma/clínica, emergência trauma/clínica, regulação médica/prévia, e ainda se a equipe está em outro atendimento), qual a natureza (programa e ambulância), no outro subitem "atendimento", foi trocado a descrição indicando se o chamado é com plano ou sem plano privado e o valor da taxa a ser cobrado.

Em seguida, ainda na Imagem 4 continua sendo indicado os valores dos "sinais vitais" em formato de tabela (horário, pressão arterial $(\mathrm{mmHg})$, frequência cardíaca $(\mathrm{bpm})$, frequência respiratória $(\mathrm{mpm})$, saturação de $\mathrm{O}^{2}$ $(\%)$, temperatura $\left({ }^{\circ} \mathrm{C}\right)$, glicemia HGT $\left.(\mathrm{mg} / \mathrm{dl})\right)$. Ainda apresenta a Escala de Coma de Glasgow (abertura ocular, resposta verbal, resposta motora, pupilas). Prosseguindo, permanece o espaço com linhas para descrição do atendimento e a conduta médica realizada pelo profissional atuante.

O penúltimo campo a ser observado na parte frontal da ficha consiste no "Controle de Gastos no Atendimento", onde são descritos quais e a quantidade de medicamentos e materiais utilizados nos procedimentos, e um item de marcação caso não tenha sido preciso o uso de insumos. No rodapé da folha permanece a assinatura do paciente ou responsável por tal, após declaração de ciência em recebimento do mencionado atendimento. Todas as informações descritas acima podem ser verificadas na Imagem 4 abaixo: 
Imagem 4. Proposta de ficha de regulação, parte frontal.

\section{FICHA DE REGULAÇÃO}

REGISTRO DE CHAMADOS

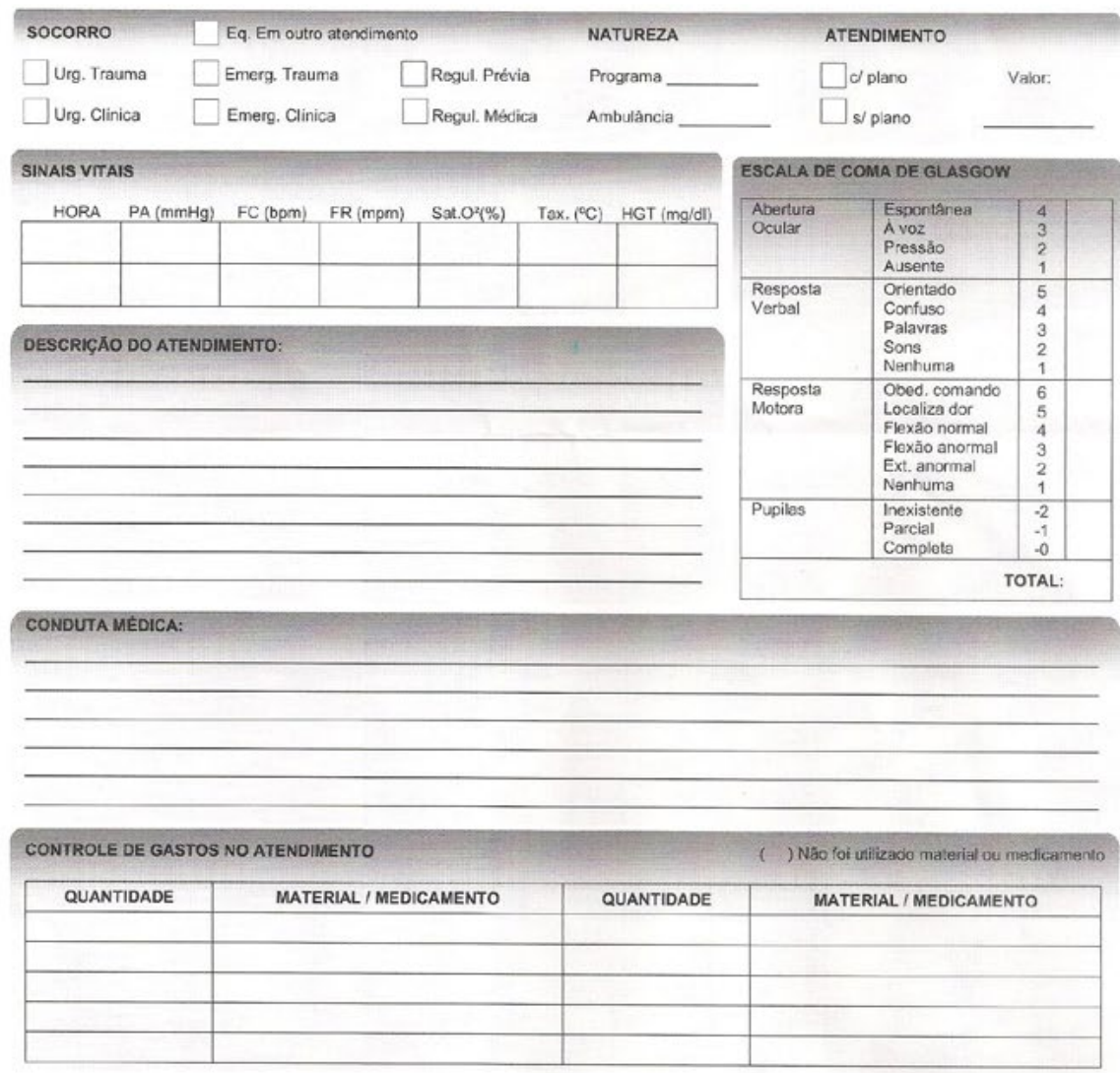

Declaro, para os devidos fins, que o atendimento do paciente mencionado foi realizado pela equipe da NOME DA EMPRESA e, portanto, comprometome à contraprostaçăo pecuniária docorrente do referido atencimento.

Paciente ou responsável

Fonte: Pesquisadores (2020). 
O verso da nova ficha proposta é demonstrado na Imagem 5, onde pode ser visualizado o primeiro campo direcionado especificamente para a "Sistematização da Assistência de Enfermagem", onde todas as etapas devem ser realizadas pelo enfermeiro ou somente o histórico/exame físico e evolução pelo técnico em enfermagem. Foram adicionados sinais e sintomas novos, buscando maior abrangência do que os pacientes possam apresentar, também foram colocados por ordem de gravidade e relevância. Ao implementar a SAE em sua completude é necessário refletir sobre a realidade do serviço e da equipe de enfermagem, de modo que as expectativas sejam cumpridas e a sensibilização sobre a realização ocorra, conforme indicam Santos e Valente (2020).

A SAE compõe-se pelos seguintes itens, que deverão ser assinalados quando correspondentes ao estado de saúde do paciente, esta etapa será preenchida pelo enfermeiro e também pelo técnico de enfermagem: histórico/ exame físico: Doenças pré-existentes (elencar as principais); Mobilidade física (deambulando sem auxilio, deambulando com auxílio, cadeira de rodas, maca, incubadora); Nível de consciência (lúcido/orientado, calmo, sonolento, agitado, confuso, síncope, sedado, coma, torporoso, crise convulsiva); respiratório (eupneico, dispneico, taquipneico, tosse. Via: máscara de Hudson, óculos nasal, traqueostomia, ventilação mecânica. Quantidade: O2_L/min); Cardiovascular (enchimento capilar: eficaz, lento, edema, extremidades frias, dormência. Mucosas: normocoradas, hipocoradas, cianóticas, ictéricas); Gastrointestinal (alimentação: ABVO, APVO, NPO, SNG, SNE, SOG, gastrostomia, jejunostomia, náuseas, vômitos. Eliminação: intestinal e vesical por via fisiológica, constipado, diarreia, uso de fraldas, ostoma, SVA, SVD. Abdômen: ruídos hidroaéreos, flácido, distendido, tenso, globoso); Tegumentar (coloração da pele: corada, hipocorada, hiperemiada, ictérica, cianótica. Alterações: lesão super., lesão prof., petéquia, úlcera, escoriação, queimadura, curativo, sutura); Osteomuscular (hematoma, luxação, entorse, fratura aberta, fratura fechada, queda). A indicação de opções a serem marcadas seguiu as especificidades do serviço dentro das possibilidades do exame físico, conforme indicado por Tannure e Pinheiro (2014).

Posteriormente foram adicionados campos abertos divididos em duas colunas para descrição de "Diagnósticos de Enfermagem" e "Prescrição de Enfermagem/Plano de cuidados". Nestes espaços são consideradas as condições de saúde, processos da vida ou situações de vulnerabilidade dos indivíduos e sua família, após esta análise busca-se oferecer direções para um cuidado individualizado ao paciente, baseado nas suas necessidades e definindo as prioridades no momento.

Seguindo, logo abaixo tem o espaço com linhas direcionado para "Implementação do plano de cuidados/Evolução de Enfermagem". Os profissionais (enfermeiros e técnicos em enfermagem) deverão descrever como foi o atendimento, bem como a conduta médica prescrita seguindo o modelo: 
Gênero, idade. Queixa principal pelo chamado. Aquilo que o profissional observa. Conduta realizada (medicação, dosagem, apresentação, via, local de aplicação). Orientações. Assinatura, carimbo.

Como finalização, foi acrescentada a última etapa da SAE em campo aberto "Avaliação da assistência de enfermagem", a qual determina a efetividade do planejamento, considerando a melhora ou não dos sintomas apresentados. Também foi adicionado um novo item que se refere em casos de necessidade de remoção, a instituição para qual o paciente foi levado, o profissional que o recebeu, com assinatura e carimbo. Todas as informações mencionadas acima podem ser verificadas na Imagem 5, abaixo:

Imagem 5. Proposta de ficha de regulação, verso.

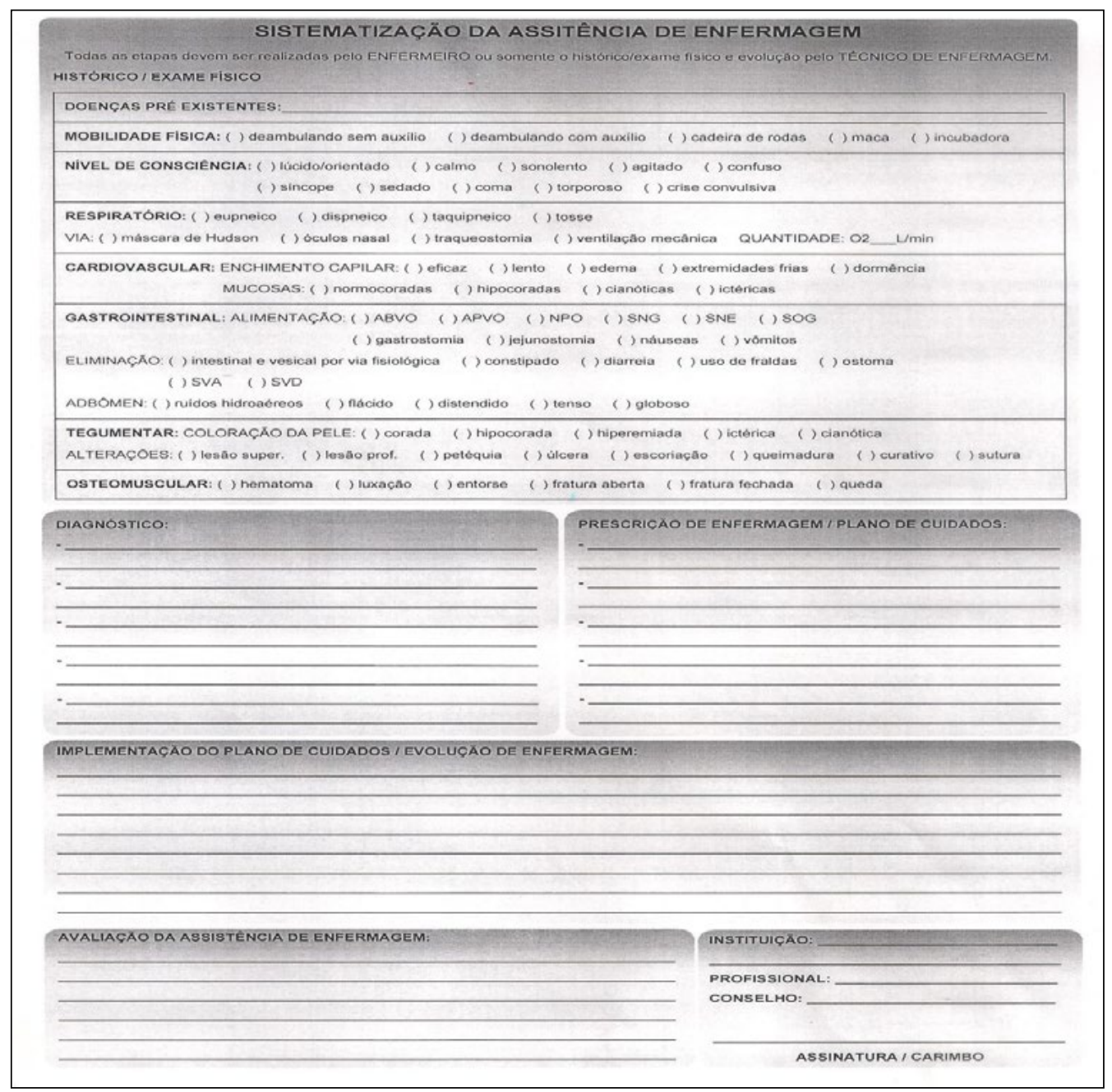

Fonte: Pesquisadores (2020). 
Após iniciar a implementação da SAE, ocorrerá a avaliação do processo por meio da auditoria dos prontuários, uma vez/mês, durante três meses. $\mathrm{E}$ após uma retomada semestral, realizada pelo enfermeiro coordenador do serviço. Será indicada a auditoria de $25 \%$ dos prontuários arquivados para verificação dos objetivos da implementação, observando detalhadamente se os campos estão preenchidos adequadamente conforme a função (enfermeiro ou técnico em enfermagem) de cada profissional da equipe, quantificando os achados. A escolha dos prontuários a serem auditados segue um sorteio aleatório entre os números de protocolo gerados nos atendimentos realizados durante o período de analise estipulado. A partir da avaliação dos prontuários, novas capacitações serão propostas em formato de educação continuada e permanente.

A realização da SAE em um serviço de saúde pressupõe o conhecimento teórico e prático do tema pelos profissionais da equipe de enfermagem, dessa forma Costa e Silva (2020) preconizam a realização de treinamentos periódicos com a finalidade de discutir melhorias no processo. Da mesma forma, Mesquita e Tavares (2020) indicam a necessidade de articular a realização de treinamentos periódicos sobre a SAE para a equipe de enfermagem, de modo de o conteúdo seja atualizado perante a legislação vigente.

\section{Considerações Finais}

Este relato de experiência possibilitou o compartilhamento de informações inerentes a implementação da Sistematização da Assistência de Enfermagem em um serviço de urgência e emergência privado do interior do Rio Grande do Sul, Brasil. Partindo das reflexões aqui dispostas, elencaram-se estratégias que possibilitam a implementação da SAE, bem como a construção de um modelo condizente com as necessidades do serviço.

A avaliação do modelo de SAE vigente aprofundou o conhecimento dos pesquisadores sobre o processo conduzido pelo serviço, bem como as oportunidades de melhoria oriundos da criticidade em que as informações foram tratadas. Por sua vez, as oportunidades de melhoria fortaleceram a necessidade de construir a capacitação para a equipe de enfermagem, instruindo os casos fictícios e inserindo os profissionais no novo modelo de ficha a ser implementado.

A construção da capacitação possibilitou a instrução de conteúdos que pactuam sobre a legislação vigente e o estudo de casos fictícios com o intuito de experimentar os profissionais na realização correta da SAE. A capacitação proposta possui um cunho educativo e de desenvolvimento da sensibilização dos profissionais como maneira de atrair uma melhor adesão ao processo.

Dessa forma, o novo modelo de ficha de regulação, com a SAE implementada em suas cinco fases apresenta-se como uma melhoria para o serviço de urgência e emergência, fortalecendo a necessidade de pactuar o 
modelo assistencial com a legislação vigente e a qualificação constante dos processos de trabalho. Esse estudo serve como base para pesquisas futuras com o intuito de aprofundar o conhecimento e as informações inerentes a implementação da SAE em serviços de urgência e emergência.

\section{Referências}

BARBOSA, A. A. R.; CASTRO, Â. T. S. Sistematização da Assistência de Enfermagem na psiquiatria: um desafio para o enfermeiro. Revista Ciência Contemporânea, v. 1, n. 6, p. 338-348, 2020.

BARDIN, L. Análise de Conteúdo. Tradução: Luís Augusto Pinheiro. São Paulo: Edições 70. 2016.

COSTA, V. F.; SILVA, V. N. Sistematização da Assistência de Enfermagem: realidade ou utopia?. Revista Ciência Contemporânea, v. 1, n. 6, p. 327-337, 2020.

FONTANA, M.; PISSAIA, L. F. O uso do processo de enfermagem como ferramenta de apoio para o cuidado da criança na atenção domiciliar. Research, Society and Development, v. 7, n. 11, p. 1371-1576, 2018.

MESQUITA, L. M. F.; TAVARES, C. M. M. Sistematização da Assistência de Enfermagem em Saúde Mental na Atenção Básica: Revisão Integrativa da Literatura. Revista Enfermagem Atual In Derme, v. 91, n. 29, 2020.

PISSAIA, L. F.; COSTA, A. E. K. Traffic medicine and first aid: interlocutions with the training of the traffic instructor. Research, Society and Development, v. 9, n. 3, p. 155932599, 2020.

PISSAIA, L. F.; COSTA, A. E. K.; THOMAS, J. Redes sociais e sala de aula: interlocuções entre os espaços/Social Networks and the classroom: dialogues between spaces. Revista Eletrônica Pesquiseduca, v. 11, n. 24, p. 233, 2020.

PISSAIA, L. F. et al. Qualificação da assistência e o ensino do Processo de Enfermagem como método de realização da Sistematização da Assistência de Enfermagem.

Research, Society and Development, v. 9, n. 6, p. 23, 2020.

PISSAIA, L.; COSTA, A. Saúde e segurança: reflexões sobre a formação do instrutor de trânsito. Research, Society and Development, v. 8, n. 9, p. e44891326, 2019.

SANTANA, R. F. Sistematização da assistência de enfermagem, uma invenção brasileira?. Revista de Enfermagem e Atenção à Saúde, v. 8, n. 2, 2020.

SANTOS, F. B.; VALENTE, G. S. C. Sistematização da Assistência de Enfermagem e a Segurança do Paciente no Ambiente Domiciliar. Enfermagem em Foco, v. 11, n. 1, 2020.

SILVA, M. C. et al. A implementação da sistematização da assistência de enfermagem no ambiente hospitalar. Brazilian Journal of Development, v. 6, n. 6, p. 33293-33306, 2020.

TANNURE, M. C.; PINHEIRO, A. M. SAE: Sistematização da Assistência de Enfermagem: Guia Prático. Rio de Janeiro, Guanabara Koogan. 2014. 